Portland State University

PDXScholar

Environmental Science and Management

Faculty Publications and Presentations

7-1-2006

\title{
Decreasing Emissions of Methane from Rice Agriculture
}

\author{
M. A. K. Khalil \\ Portland State University, aslamk@pdx.edu \\ Martha J. Shearer \\ Portland State University
}

Follow this and additional works at: https://pdxscholar.library.pdx.edu/esm_fac

Part of the Environmental Sciences Commons

Let us know how access to this document benefits you.

\section{Citation Details}

Khalil, M. A. and Shearer, Martha J., "Decreasing emissions of methane from rice agriculture" (2006). Environmental Science and Management Faculty Publications and Presentations. Paper 12. http://archives.pdx.edu/ds/psu/7593

This Post-Print is brought to you for free and open access. It has been accepted for inclusion in Environmental Science and Management Faculty Publications and Presentations by an authorized administrator of PDXScholar. Please contact us if we can make this document more accessible: pdxscholar@pdx.edu. 


\section{Editorial Manager(tm) for International Congress Series}

Manuscript Draft

Manuscript Number: 1293068-52R1

Title: Decreasing emissions of methane from rice agriculture

Article Type: Full Length Article (FLA)

Section/Category:

Keywords: : rice agriculture; methane, nitrous oxide; emission factor; greenhouse gas

Corresponding Author: Dr. M. Aslam K. Khalil,

Corresponding Author's Institution: Portland State University

First Author: M. Aslam K. Khalil

Order of Authors: M. Aslam K. Khalil; M. Aslam K. Khalil; Martha J. Shearer

Manuscript Region of Origin:

Abstract: Methane emissions from rice fields are controlled by several key factors. The most important are the application of organic soil amendments and water management: whether the fields are flooded intermittently or continuously. The total annual emissions from any country or the world are thus affected by the area of rice harvested, and a composite emission factor that takes into account how the various agricultural practices are distributed in terms of fertilizer use and water management, as well as other less important variables. Over decades the area of rice harvested changes but so does the composite emission factor. The product therefore, may change substantially over decadal time scales. We will argue that for China at least, there are downward trends of both area and emission factor leading to a substantial reduction of annual emissions over the last two decades from some $30 \mathrm{Tg} / \mathrm{yr}$ to perhaps less than $10 \mathrm{Tg} / \mathrm{yr}$. The changes that cause these reductions would increase nitrous oxide emissions from rice fields as organic fertilizers are replaced with nitrogen based fertilizers. Similar changes are likely to be occurring world-wide. These trends of emissions are probably represented in the observed slowdown of methane trend in the atmosphere and the continuing steady increase of nitrous oxide. 


\title{
Decreasing emissions of methane from rice agriculture
}

\author{
M.A.K. Khalil ${ }^{\mathrm{a}}{ }^{*}$ and M.J. Shearer ${ }^{\mathrm{b}}$ \\ ${ }^{a}$ Department of Physics, Portland State University, Portland, Oregon, USA \\ ${ }^{b}$ Environmental Science and Resources Program, Portland State University, Portland, Oregon, USA
}

\begin{abstract}
Methane emissions from rice fields are controlled by several key factors. The most important are the application of organic soil amendments and water management: whether the fields are flooded intermittently or continuously. The total annual emissions from any country or the world are thus affected by the area of rice harvested, and a composite emission factor that takes into account how the various agricultural practices are distributed in terms of fertilizer use and water management, as well as other less important variables. Over decades the area of rice harvested changes but so does the composite emission factor. The product therefore, may change substantially over decadal time scales. We will argue that for China at least, there are downward trends of both area and emission factor leading to a substantial reduction of annual emissions over the last two decades from some $30 \mathrm{Tg} / \mathrm{yr}$ to perhaps less than $10 \mathrm{Tg} / \mathrm{yr}$. The changes that cause these reductions would increase nitrous oxide emissions from rice fields as organic fertilizers are replaced with nitrogen based fertilizers. Similar changes are likely to be occurring world-wide. These trends of emissions are probably represented in the observed slowdown of methane trend in the atmosphere and the continuing steady increase of nitrous oxide.
\end{abstract}

Keywords: rice agriculture; methane, nitrous oxide; emission factor; greenhouse gas

\section{Introduction}

It is well known that human activities are adding gases to the atmosphere that will cause global warming. While many gases have been identified and examined, in the end only three stand out as having a significant potential - these are carbon dioxide $\left(\mathrm{CO}_{2}\right)$, methane $\left(\mathrm{CH}_{4}\right)$, and nitrous oxide $\left(\mathrm{N}_{2} \mathrm{O}\right)$. The other non- $\mathrm{CO}_{2}$ greenhouse gases have a much more tenuous potential for causing global warming even when taken collectively. Taking control of global warming requires a comprehensive approach to limit the emissions of at least these three greenhouse gases. While the dominant source of manmade $\mathrm{CO}_{2}$ is fossil fuel burning, various agricultural activities are the major source of methane and nitrous oxide [1-3 and Fig 1]. There are many uncertainties in the estimates

\footnotetext{
* Corresponding author. Tel: +1 503 725-8396 Fax: +1 503 725-8550 E-mail address: aslamk@pdx.edu. M.A.K Khalil, Dept. of Physics, Portland State University, P.O. Box 751, Portland, OR 97207-0751, USA.
} 
of individual sources and the details shown in the figure may be disputed, but the fact that agricultural sources contribute a third to a half of the man-made emissions of these gases is more certain. The fuller understanding of each of these sources and the factors that control them is a very large and active area of research. The goal of this paper is to focus on a much narrower but important field dealing with methane emissions from rice fields and implications for nitrous oxide.

Every budget of methane has shown that rice fields are a significant fraction of the global emissions[4]. Less has been written about nitrous oxide, but it is apparent that in recent years rice fields have become important in its budget also[5,6]. The main thesis of this paper is that methane emissions from rice fields have been falling in recent decades and at the same time nitrous oxide emissions have been increasing. These changes are so dramatic, that to be effective, environmental policies for controlling global warming must take them into account.
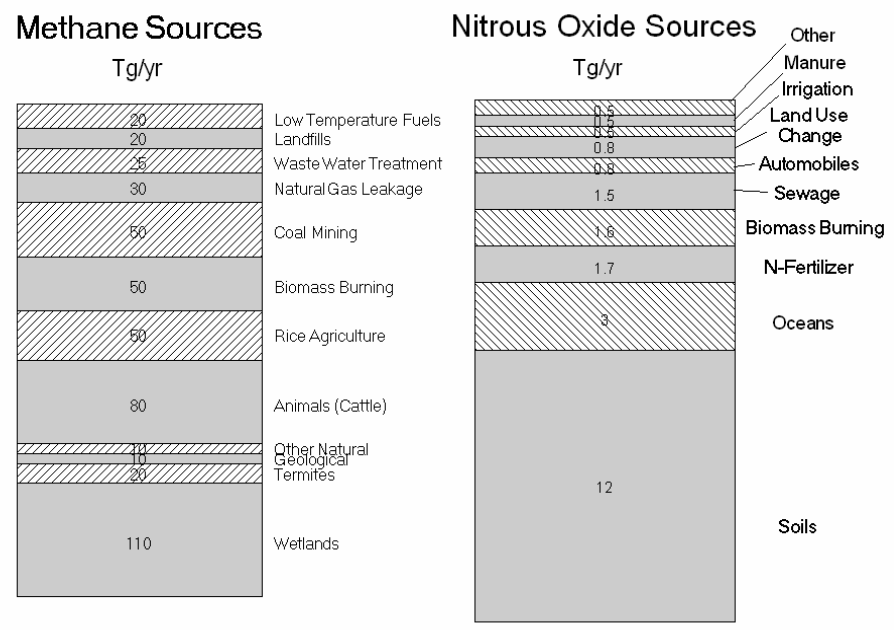

Fig. 1. The sources of methane and nitrous oxide. The annual emissions from various sources are organized as natural and man-made and within these groupings, are arranged with the largest at the bottom to the smallest on the top. Some of these positions may change depending on the budget and what year the emissions represent. Sources have changed at different rates over the last decades.

\section{Focus on methane emissions from rice fields}

It may interest the reader to review the processes that cause methane emissions from rice fields in particular and from wetland areas in general. The rice paddy system essentially consists of four zones. On the top there is some $2-5 \mathrm{~cm}$ of water when the field is inundated. Below this is some $20-30 \mathrm{~cm}$ of puddled fully saturated soil. A fraction of this zone, that increases over the growing season, is taken up by the roots. This rhizosphere or root zone is separated from the similar adjacent soil without roots. 
Below this tilled layer is the compacted foundation which has low percolation rates allowing the fields to stay inundated for long periods of time.

We divide the process of methane emissions into three closely coupled steps: First, the organic matter is applied and incorporated into the soils that will eventually supply the carbon needed for methane emissions. The main source is often organic fertilizer, but other sources include leftover soil carbon from previous years, straw, roots and organic compounds supplied by root exudation. This carbon has to go through a number of decomposition steps involving various types of bacteria before it can be utilized by methanogens that produce methane. It is important to note that methanogens exist in strictly anaerobic environments. The deeper soil of the rice field, inundated with water generally creates the anaerobic conditions needed for methanogens to live. The second step is the transport of this deeper methane and its oxidation on the way to the atmosphere. The oxidation is found to take place mostly in the root zone which has a supply of oxygen from the plant. In this root zone, or possibly just inside the root, are methanotrophic bacteria that utilize methane as a source of energy or food. Their aerobic metabolism consumes methane and produces $\mathrm{CO}_{2}$. The final step is the transport of methane out of the paddy system and into the atmosphere. There are several pathways: bubbles; diffusion through the soil and water; and the transport of the methane through the root to the plant. Of these the bubbles are perhaps important only in the early stages of rice growth. Later, a very large fraction is the transport through the plant. This is in part because the oxidation creates strong gradients that move methane through the root zone while other pathways are less efficient. What gets out into the atmosphere through the plant is the residue of the methane that does not get oxidized by the methanotrophs [see for example:7,8].

Over the years a large number of field studies have been carried out to measure whole season methane fluxes from rice fields in various parts of the world. The seasonally averaged results have been extremely variable, ranging from low emission rates of 1-2 $\mathrm{mg} / \mathrm{m}^{2} / \mathrm{hr}$ to more than $30 \mathrm{mg} / \mathrm{m}^{2} / \mathrm{hr}$. Field studies have tested the influence of various factors on methane emissions, such as cultivar, soil properties, soil temperature, fertilizer use and water management. While effects have been reported for various factors, the latter two appear to be the most significant related to agricultural practices. The wide variation of emissions observed is no longer a puzzle, but it is still not possible to explain all the data in terms of known factors, mostly because all relevant factors are rarely measured. Roughly, with continuous inundation and plenty of organic matter, seasonal average methane emissions are $20-40 \mathrm{mg} / \mathrm{m}^{2} / \mathrm{hr}$, while intermittent flooding with organic fertilizers results in $5-15 \mathrm{mg} / \mathrm{m}^{2} / \mathrm{hr}$, with low organic inputs the emissions can drop to 1 $5 \mathrm{mg} / \mathrm{m}^{2} / \mathrm{hr}$ and are especially low when there is intermittent flooding of the fields [9]. Generally, low organic fertilizer applications are compensated by nitrogen based fertilizers which increase nitrous oxide emissions.

A heuristic model can make this picture more quantitative and help explain the present results. In its simplest form it consists of a mass balance of methane between two main soil reservoirs: the production $\left(\mathrm{V}_{\mathrm{S}}\right)$ and the root zones $\left(\mathrm{V}_{\mathrm{R}}\right)$.

$\mathrm{d} / \mathrm{dt}\left(\mathrm{C}_{\mathrm{S}} \mathrm{V}_{\mathrm{S}}\right)=\mathrm{PV}_{\mathrm{S}}-\left(\mathrm{C}_{\mathrm{S}}-\mathrm{C}_{\mathrm{R}}\right) \mathrm{V}_{\mathrm{S}} / \tau_{\mathrm{S}}$ 


$$
\begin{aligned}
& \mathrm{d} / \mathrm{dt}\left(\mathrm{C}_{\mathrm{S}} \mathrm{V}_{\mathrm{R}}\right)=\left(\mathrm{C}_{\mathrm{S}}-\mathrm{C}_{\mathrm{R}}\right) \mathrm{V}_{\mathrm{S}} / \tau_{\mathrm{S}}-\left(1 / \tau_{\mathrm{O}}+1 / \tau_{\mathrm{P}}\right) \mathrm{C}_{\mathrm{R}} \mathrm{V}_{\mathrm{R}} \\
& \Phi=\mathrm{C}_{\mathrm{R}} \mathrm{V}_{\mathrm{R}} / \tau_{\mathrm{P}}
\end{aligned}
$$

Where $\mathrm{P}$ is the production $\left(\mathrm{g} / \mathrm{m}^{3}-\mathrm{s}\right), \mathrm{V}_{\mathrm{S}}$ and $\mathrm{V}_{\mathrm{R}}$ are the volumes of the soil and root zones $\left(\mathrm{m}^{3}\right)$ in the field, $\tau$ 's are the transport or residence times (in s) from the soil production zone to the root zone $\left(\tau_{\mathrm{S}}\right)$ and from the root zone into the plant through the root $\left(\tau_{\mathrm{P}}\right) ; \tau_{\mathrm{O}}$ is the characteristic lifetime due to oxidation in the root zone; and $\mathrm{C}_{\mathrm{S}}$ and $\mathrm{C}_{\mathrm{R}}$ are the concentrations in the soil and the root zone respectively $\left(\mathrm{g} / \mathrm{m}^{3}\right)$. These equations can be integrated over the whole growing season so that the integrals of the left hand sides are zero because at both times no significant amounts of methane exist in the soil. It can be shown that the net flux $\Phi(\mathrm{g} / \mathrm{s})$ from the whole field, in terms of the processes is:

$$
\bar{\Phi}=\overline{\mathrm{P}} \overline{\mathrm{V}_{\mathrm{S}}} /\left(1+\overline{\tau_{\mathrm{P}}} / \overline{\tau_{\mathrm{O}}}\right)
$$

We see, as may be expected, that the emissions are proportional to production, but that the proportionality is affected by the oxidation and transport processes that couple together. The overbars reflect the fact that these are integrated values and for the $\tau$ 's these are the mass (of methane) weighted averages, so they represent effective oxidation and transport times into the plant which include many complexities and feedbacks.

Based on our earlier discussion, for there to be production of methane, both a supply of organic material and anaerobic conditions are needed; the latter in the case of rice fields require inundation of the fields by water. Thus the flux must depend fundamentally on these two factors as it is directly proportional to the production. All the remaining processes and factors are included in the ratio of the effective transport and oxidation times $\left(\tau_{\mathrm{P}} / \tau_{\mathrm{O}}\right)$. Experiments show that this ratio is $\sim 5$ or so reflecting the observation that most $(50 \%-90 \%)$ of the methane that is produced is oxidized. This ratio includes the effects of rice cultivars in terms of the root characteristics and volumes that determine $\tau_{\mathrm{P}}$ for instance, populations of methanotrophs, temperature and density of planting. It is probable that this ratio does not change much in practice since it involves factors not directly affected by agricultural processes or productivity. These arguments support the field results and the idea that organic matter applications and water inundation are the main factors that affect methane emissions from rice fields.

\section{China: Case study.}

China has produced $20 \%-30 \%$ of the world's rice for many decades and hence has been the focus of extensive field and laboratory studies to determine the annual emission rates. The most extensive data related to year by year changes of emissions are available from China, which we will use to estimate the decreases of emissions.

Country-wide annual emissions are calculated as $\mathrm{S}(\mathrm{g} / \mathrm{yr})$ by the following equations:

$S(t)=E(t) A(t)$ 


$$
\mathrm{E}=\sum_{\mathrm{i}} \varphi_{\mathrm{T}_{\mathrm{i}}} \mathrm{A}_{\mathrm{i}} / \sum_{\mathrm{i}} \mathrm{A}_{\mathrm{i}}
$$

Where $\mathrm{E}$ is the area weighted emission factor; $\varphi_{\mathrm{Ti}}=$ Total flux measured over the growing season for field of type "i", $\left(\mathrm{g} / \mathrm{m}^{2}\right) ; A_{i}=$ Area harvested per year $\left(\mathrm{m}^{2} / \mathrm{yr}\right)$ for field of type " $i$ ", $A=$ Total area harvested $\left(\mathrm{m}^{2} / \mathrm{yr}\right)$.

The equation for the annual emissions is the product of two variables: the area weighted average, or composite emission factor; and the total area harvested. Records for the total area harvested are readily available and show decadal trends. These are normally taken into account when calculating the changes in the annual emission rates. But the average emission factor also changes in time due to the shifting nature of agricultural practices. For the case of China, the changing emission factor may be more significant than the change in the area of rice harvested.

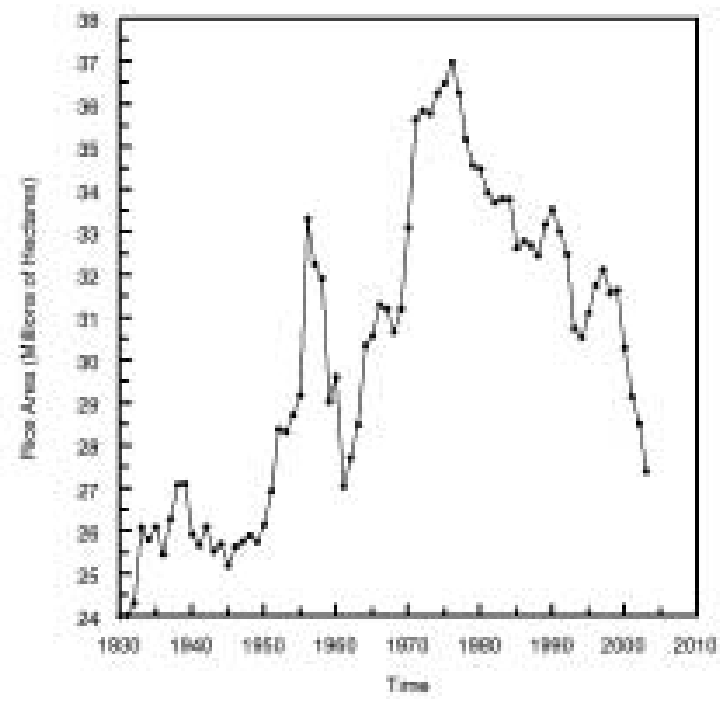

Fig. 2. The area of rice harvested in China over the last 80 years. Of particular importance to the present paper is the decrease of area in recent decades during which time intensive emissions measurements have been taken.

The area of rice harvested in China is shown for the last 30 years in Fig. 2. Here we see an increase up to the late 1970s and a systematic decline since then. This change is about $-14 \%$ from the peak areas and though important is not the only change that has occurred. The changes in area have followed economic and social trends in China. At least three factors are responsible: pullback from marginal areas for rice agriculture, development of high yielding varieties and diversification of crops. The latter is quite significant in the southern part of China where multiple rice crops are replaced with a rotation of vegetables or other grains that are more profitable. These changes follow recent liberalization of economic and social policies.

The emission factors also have declined substantially but the quantitative change is still difficult to estimate. There are two major factors that have affected the composite 
emission factor that go to the heart of the methane production from rice fields and also affect nitrous oxide emissions. In recent years, nitrogen based fertilizers have replaced organic manure in many fields and the transition is still continuing. As less decomposable organic matter is supplied, the methane production is reduced. The second is that for various reasons, rice fields are more often intermittently flooded and in more locations than before. The water use trends are even more difficult to quantify than fertilizer use, but that decreases have occurred is well known [10].

We carried out three calculations for the composite emission factor: No change in emission factors, change in organic fertilizer applications and changes in both fertilizer and water regimens. The time series of annual emissions was calculated by first creating a time series of rice area harvested in each province and municipality of China for which statistics are kept [11-13]. Municipalities such as Beijing and Shanghai were included. If provincial records were unavailable, then the average fraction of area in each province over adjacent years was applied to the total area harvested in China to estimate the provincial area $[14,15]$.

For the initial estimate, only the area $\left(\mathrm{A}_{\mathrm{i}}\right)$ varied with time. The fluxes were originally assigned to the provinces by major climatic regions published by Gao [16] since at the time there were few flux measurements from China [17-20]. The number of days in the growing season was estimated using the seasonality given by Matthews et al. [21], and modified by the observed number of days between planting and harvest. The areas in each province are divided by the water management type after Huke [22]. The fluxes are modified for rainfed rice to be half the rate of the flooded rice area, and flux is 0 for upland or dryland rice.

For the next estimate the effect of organic fertilizer trends was applied to the annual totals. Organic fertilizers were applied at their highest rate in China during the late 1970s as documented by Wen [23] and Yuan [24]. In the 1950s, adding organic matter to increase soil fertility was made a national goal, and all available sources were used. However, areas planted to green manure are better documented than other sources of organic matter. Areas increased greatly between 1960 and 1975 then declined as mineral fertilizers became available in greater quantities starting in the 1980s [25]. Interviews with agricultural agents in 20 districts of Sichuan province indicate that if the farmers can afford mineral fertilizer, then they will stop using animal manures and night soil [Khalil, unpublished results]. Methane fluxes from rice fields are assumed to increase slightly between 1960 and 1980, using the results on organic matter applications from Chen et al. [17] and Wassmann et al. [18], then declines by about half to 2000, where fluxes stabilize [9, and references therein; 26].

The last calculation is for changes due to water management. Mid-season drying either due to drainage or evaporation is assumed to increase as pressure on water resources increases. The use of field draining is assumed to increase in the mid-1980s, and continue with reductions from there [27]. This part of the calculation remains the most tenuous since data on changes in water usages are difficult to gather and validate. Some of our assumptions of reduction are based on a set of interviews conducted in Sichuan Province in 1999-2000 with farmers and agricultural agents. These interviews confirmed that water use changes have been occurring and a rough quantification was obtained from these. 
Finally the emissions calculated as the product of the changing emission factors and the changing area harvested according to Eqn. 5 are shown in Fig. 3 below. It is clear that reductions in area have a relatively small effect on the trends of annual emissions from China while changes in emission factors may result in a substantially greater reduction. Li et al. $[27,28]$ using an intensive modelling approach, also show a large decrease in methane emission from Chinese rice fields after 1980.

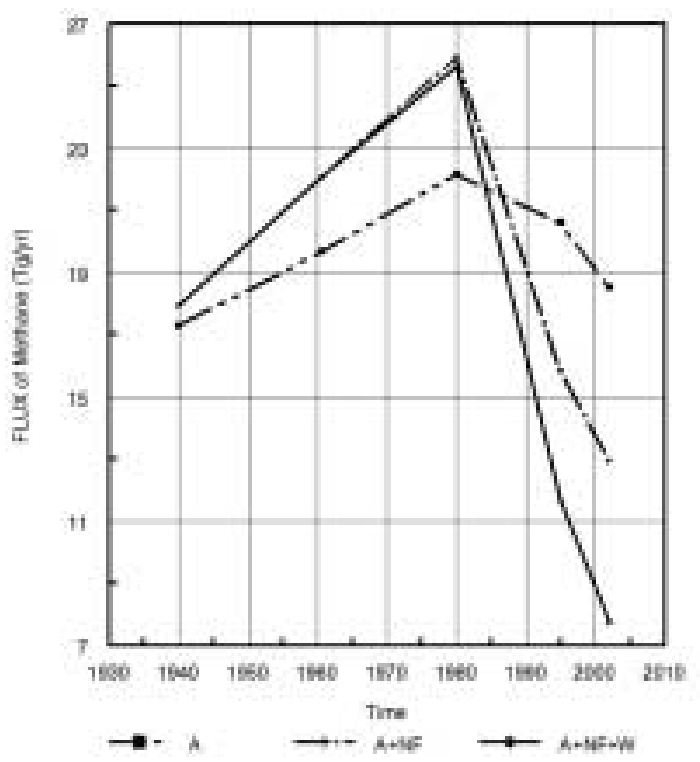

Fig. 3. Estimated emissions of methane from rice fields in China over the last 60 years. The results are reported as averages for 10 year increments until the most recent time, which is an average over 5 years. The highlight is the reduction in emissions over the last 2-3 decades. While some is driven by reduced area, even more reductions have probably occurred due to reductions in the composite emission factor. $\mathrm{A}=\mathrm{Area}$ only, $\mathrm{A}+\mathrm{NF}=$ Area and nitrogen fertilizer change, $\mathrm{A}+\mathrm{NF}+\mathrm{W}=$ Area, fertilizer and water use changes.

\section{Extrapolations and connections}

Although the combination and the magnitude of the changes seen in China are not duplicated elsewhere, increased use of nitrogen fertilizers has occurred in other rice growing countries. The global area of rice from countries other than China increased at about $100 \mathrm{Mha} / \mathrm{yr}$ between 1960 and 1980, but only at $57 \mathrm{Mha} / \mathrm{yr}$ between 1980 and 2000 - a significant slowing in recent years as yields have increased both because of hybrid varieties and the use of nitrogen fertilizers. The use of nitrogen fertilizers world wide has doubled over the last 30 years or so. Although we are not certain how much of it is used for rice crops, the area of rice has increased only by about $15 \%$ during this time. There is an implication that much more nitrogen fertilizer is probably being applied to the rice fields than in previous decades. Hence it is very likely that methane 
emissions from rice fields in other parts of the world have also decreased from peak values some two decades ago or earlier. Our calculations show that reductions from China alone are of the order of $20 \mathrm{Tg} / \mathrm{yr}$ and it is only about $20 \%$ of the world's rice area. Conservative estimates of reductions from the rest of the world would suggest another $10-50 \mathrm{Tg} / \mathrm{yr}$ reductions in methane emissions. Hence the total methane emissions from rice fields may have gone from some $90 \mathrm{Tg} / \mathrm{yr} 30$ years ago down to as low as $20-50 \mathrm{Tg} / \mathrm{yr}$ now. This change is consistent with observations of other aspects of the global methane budget including the decreasing trend, which we believe is perhaps mostly due to the reduction in methane emissions from rice fields. Many uncertainties remain in these calculations, but it is not possible to quantify these at present.

One consequence of the changes we have discussed is that nitrous oxide emissions from rice fields may well be increasing. For the case of China, both factors: increased use of nitrogen fertilizers and intermittent flooding, are likely to increase nitrous oxide emissions, while for the rest of the world the increase of fertilizer use would do the same. At present there are several key data sets on the emissions of nitrous oxide from rice fields but these are not sufficient to fully evaluate the global or country-wide emission rates with confidence, much less any trends over the last several decades. It is well known however that nitrous oxide concentrations are increasing in the atmosphere and the rates are consistent with world fertilizer use trends (see Fig 1). It also seems evident that rice fields are contributing an increasing share of the already sizable fertilizer nitrous oxide component. Nonetheless, it seems that the reduction of methane emissions is not completely offset by the increase of nitrous oxide in terms of radiative forcing. It remains the subject of our continued investigations to quantify these relationships.

\section{Acknowledgements}

We have benefited from discussions with many colleagues including Prof. R.A. Rasmussen, (OGI School of Science), Chris Butenhoff and Zhengqin Xiong (Portland State University) and our colleagues in China: $\mathrm{Li} \mathrm{Xu}$ (Chinese Meteorological Adminsitration, Beijing) and Chang-Ling Duan (Chinese Academy of Sciences, Chengdu). Major support for this work was supported by grants from the U.S. Department of Energy, Office of Science (BER), Grant Nos. DE-FG03-01ER63262 and DE-FG02-04ER63913. Additional support was provided by the resources of Andarz Co.

\section{References}

[1] M.A.K Khalil, R.A. Rasmussen, The global sources of nitrous oxide, J. Geophys. Res. 97 (1992), 14651-14660.

[2] M.A.K. Khalil, (ed) Atmospheric Methane: Sources, Sinks and Role in Global Change, Springer-Verlag, Berlin, 1993.

[3] Khalil, M.A.K., (ed) Atmospheric Methane: Its Role in the Global Environment, SpringerVerlag, Berlin, 2000.

[4] M.A.K Khalil, R.A. Rasmussen, Constraints on the global sources of methane and an analysis of recent budgets, Tellus 42B (1990), 229-236.

[5] Z.-C. Cai et al., Measurements of $\mathrm{CH}_{4}$ and $\mathrm{N}_{2} \mathrm{O}$ emissions from rice paddies in Fengqiu, China, Soil Sci. Plant Nutr. 45 (1999), 1-13. 
[6] K.F. Bronson, H.-U. Neue, U. Singh, E.B. Abao, Jr., Automated chamber measurements of methane and nitrous oxide in a flooded rice soil: I. Residue, nitrogen, and water management, Soil Sci. Soc. Am. J. 61 (1997), 981-987.

[7] H.-U. Neue, P.A. Roger, Rice agriculture: Factors controlling emissions, Atmospheric Methane: Its Role in the Global Environment, Springer-Verlag, Berlin, 2000.

[8] D. Boone, Biological formation and consumption of methane, Atmospheric Methane: Its Role in the Global Environment, M.A.K.Khalil, (Ed), Springer-Verlag, Berlin, 2000.

[9] M.J. Shearer, M.A.K. Khalil, Rice agriculture: Emissions. In: Atmospheric Methane: Its Role in the Global Environment. M.A.K. Khalil, Ed. Springer-Verlag, Berlin, Germany, 2000.

[10] R. Loeve et al., Long-term trends in intersectoral water allocation and crop water productivity in Zhanghe and Kaifeng, China, Paddy Water Environ. 2 (2004) 237-245.

[11]China Agricultural Yearbook, Agricultural Publishing House, Beijing, China, 1985-1988.

[12]IRRI, World Rice Statistics 1990, 2000. International Rice Research Institute, Manila, Philippines, 1991,2001.

[13]USDA Statistical Bulletin No. 714, Agricultural Statistics of the People's Republic of China, 1949-82. Washington, D.C., 69 p., 1984.

[14]B.R. Mitchell, International Historical Statistics Africa, Asia and Oceania, $4^{\text {th }}$ Ed. 1750 2000. Palgrave MacMillan, Basingstoke, Great Britain, 2003.

[15]UNFAO statistical website http://faostat.fao.org/ Agricultural Production, Primary Crops, Rice Area harvested, China.

[16]L.-Z. Gao, L. Li, Z-Q. Jin, A climatic classification for rice production in China. Ag. and For. Meteor. 39 (1987) 55-65.

[17]Z.-L Chen., D.-B Li., K.-S. Shao, B.-J. Wang, Features of $\mathrm{CH}_{4}$ emission from rice paddy fields in Beijing and Nanjing. Chemosphere 26 (1993) 239-245.

[18]R. Wassmann et al., Quantification of methane emissions from Chinese rice fields (Zhejiang Province) as influenced by fertilizer treatment. Biogeochemistry 20 (1993) 83-101.

[19]M.A.K. Khalil et al., Measurements of methane emissions from rice fields in China. J. Geophys. Res. 103 (1998) 25,181-25,210.

[20]M.A.K. Khalil et al., Emissions of methane, nitrous oxide, and other trace gases from rice fields in China. J. Geophys. Res. 103 (1998) 25,241-25,250.

[21]E. Matthews, I. Fung, J. Lerner. Methane emission form rice cultivation: Geographic and seasonal distribution of cultivated areas and emissions. Global Biogeochem Cycles 5 (1991) $3-24$.

[22] R.E. Huke, Rice Area by Type of Culture: South, Southeast, and East Asia, International Rice Research Institute, Los Baños, Philippines, 1982.

[23]Q.-X. Wen Utilization of organic materials in rice production in China. In: Organic Matter and Rice, International Rice Research Institute, Los Baños, Philippines, (1984) p. 45- 56.

[24]C.-Y. Yuan, The utilization of animal and human wastes in rice production in China. In: Organic Matter and Rice, International Rice Research Institute, Los Baños, Philippines, (1984) p. 179-192.

[25]H. Denier van der Gon. Changes in $\mathrm{CH}_{4}$ emission from rice fields from 1960 to $1990 \mathrm{~s}$ 2. The declining use of organic inputs in rice farming. Global Biogeochem Cycles 13 (1999) 10531062.

[26]X. Yan, K. Yagi, H. Akiyama, H. Akimoto. Statistical analysis of the major variables controlling methane emission from rice fields. Global Change Biology 11 (2005) 1131-1141.

[27]C. Li et al. Reduced methane emissions from large-scale changes in water management of China's rice paddies during 1980-2000. Geophys Res Lett 29 (2002) doi:10.1029/2002GL015370.

[28] C. Li et al. Modeling impacts of farming management alternatives on $\mathrm{CO}_{2}, \mathrm{CH}_{4}$, and $\mathrm{N}_{2} \mathrm{O}$ emissions: A case study for water management of rice agriculture of China. Global Biogeochem Cycles 19 (2005) GB3010 doi: 10.1029/2004GB002341. 
Your PDF file "ICS_Khalil_figures.pdf" cannot be opened and processed. Please see the common list of problems, and suggested resolutions below.

Reason: Could not open the PDF: ICS_Khalil_figures.pdf

Other Common Problems When Creating a PDF from a PDF file

You will need to convert your PDF file to another format or fix the current PDF file, then re-submit it. 
Reply to Reviewer \#1:

There are a few points that need a reply rather than a revision of the manuscript. First, as a comment, we believe these results are original and new. The whole issue of changing emission factor is a new idea and has been treated in very few publications. The idea of decrease in organic fertilizer use has not been discussed before. Furthermore our method is entirely independent of previous evaluations and the results are different.

As to the question of increasing nitrous oxide emissions. The data on $\mathrm{N} 2 \mathrm{O}$ are presently very limited and any calculation about the radiative impacts would take us too far afield from the subject of the paper. It may be possible to make an estimate by using a model for past and present emissions such as that by Li et al. (2004) mentioned by the reviewer. But we are basing our results directly on observations and hence have no estimate of nitrous oxide emission changes at this time. A brief qualitative comment has been added.

The figures have been sent to the publisher in high quality pdf format, as specified in manuscript preparation directions.

Specific comments - corrections made.

Reply to Reviewer \#2:

1. The nature of the work is such that we cannot quantify the uncertainties at this time. Any attempt to do so at this point would be fairly arbitrary. The research is continuing and we hope to be able to do an uncertainty analysis in the future. A brief qualitative statement has been added.

2. New references cited.

3. Figures revised. (see above) 